SHS Web of Conferences 12,01091 (2014)

DOI: $10.1051 /$ shsconf/ 20141201091

(C) Owned by the authors, published by EDP Sciences, 2014

\title{
Local Sabahans' Satisfaction with Level of Access to Mount Kinabalu
}

\author{
Christy Bidder ${ }^{1}$, Reni Cacillia Polus ${ }^{2}$ \\ ${ }^{1}$ Faculty of Hotel and Tourism Management, Universiti Teknologi MARA, 88997 Sabah, Malaysia \\ ${ }^{2}$ Faculty of Hotel and Tourism Management, Universiti Teknologi MARA, 94300 Sarawak, Malaysia
}

\begin{abstract}
This study analyzes the local Sabahans' satisfaction with the level of access to Mount Kinabalu in Sabah, Malaysian Borneo. Specifically, it examines the number of complaints by local Sabahans regarding access and their perception of changes in accessibility to the mountain. Interviews with Sabah Parks and Sutera Sanctuary Lodges were conducted and questionnaires were distributed to local residents to collect data. The results show that there were intense complaints regarding the climbing cost and extensive waiting time to secure a confirmed booking at the outset of price increases. However, the researchers could not locate any recently published complaints. Respondents who have previously climbed Mount Kinabalu perceive the mountain to be less accessible for local Sabahans now due to a less affordable cost and a longer waiting time. Those who have not climbed Mount Kinabalu also think the climbing cost has become less affordable for local Sabahans, but they do not perceive that to be causing the mountain less accessible for local Sabahans.
\end{abstract}

\section{Introduction}

In some places, formerly public places (shorelines or forests) may become privatized at the expense of perceived or real access of the local residents. They may be displaced by visitors or priced out of regular use [1]. For instance, a quarter of Boracay Island in the Philippines has been sold to outside corporations resulting in a water supply crisis and limited infrastructure benefits for residents [2]. In Bali Indonesia, the major agricultural land and water supplies have been redirected for the use of large hotels and golf courses [2].

In Pangandaran Indonesia, a village beach land that was conventionally utilized for grazing, repairing boats and nets and holding festivals was bought by entrepreneurs for a five-star hotel [2]. Change in access by local residents is a specific subset of tourism impact on the host community. It may be closely related to the local residents' overall satisfaction with tourism development [1]. This particular investigation looks at local Sabahans' satisfaction with the level of access to Mount Kinabalu. This objective is based on one of the components, or indicators, of access suggested by WTO [1]. 


\section{Literature Review}

In many areas of the world, parks are typically owned and managed by the public sector, who is usually short on tourism competencies and professional expertise (e.g. in tourism economics, marketing, tourism management, and service quality). Moreover, the public sector is usually financially constrained and lacks the necessary resources to conserve nature and provide visitor facilities to attend to the increasing public demand [3-4]. Such shortages pave the way for the introduction of privatization in management of tourism resources. Often the private sector has much higher levels of tourism market expertise and resources (capital and manpower) than does the public sector. Thus, the former is much more capable of attracting visitors, servicing their needs and providing all of the tourism services [3].

The private sector often acts as a provider of tourism services including accommodation, restaurants, tour operations, waste collection, site maintenance and information provision, in the form of concessionaires [5]. In particular, the private sector is able to offer high standard tourism services to meet the demand and expectation of tourists [5]. Undoubtedly, the provision of a high quality tourism experience comes with higher costs. The profit earned from this experience is the incentive to achieve outstanding service and uphold the status of the destination. Additionally, with the private sector taking care of tourism facilities and services, the public sector can use its available human and financial resources to provide public services (i.e. nature conservation and welfare of local communities) [5].

However, the private sector is driven by profit. Thus, if it is not monitored, private operators with selfish personal agendas can cause overuse of tourism resources, thereby degrading the environment [3]. It is upsetting that in tourism public-private partnerships, the private sector seems to have acquired total domination [4]. Because of this, the governments are becoming weaker in their decision-making power, making way for the private sector to commandeer public agendas. The monopoly of a private tourism operator can often cause devastating consequences for local people and the environment [4].

In 1998, Sabah Parks (SP hereafter) privatized the accommodation and catering facilities in Kinabalu Park to Sutera Sanctuary Lodges (SSL hereafter). The rationale behind this privatization is to increase the number of visitors and improve tourism facilities and services in the park to meet visitor expectations. The program was also introduced to provide job opportunities for the local communities in a tourism-related business.

Furthermore, it was hoped that with the privatization, the administrative, manpower and financial responsibilities of SP would be lessened, thereby allowing it to focus on conservation efforts [7-8]. In 2007, SSL increased the cost of accommodations on Mount Kinabalu and other properties in Kinabalu Park. The cost of a dorm bed jumped from RM30 to RM188 (meals included). That was an increase of about $500 \%$. In 2009, the cost of the package was further increased to RM330 per person [7, 8]. Prior to privatization, climbers had an option to bring their own food, thereby saving some cost [7].

It is imperative that those responsible for the planning of tourism work toward optimizing the welfare of local residents while keeping the costs of tourism development to a minimum [9]. Critical to the success and sustainability of the tourism industry is the support of destination communities for tourism [9-10], or what is termed as a 'happy host' [11]. Local communities will usually withdraw their support for tourism if they perceive the costs of tourism to prevail over the benefits, thereby jeopardizing the future success and development of the industry [12].

For-profit tourism undertakings may be hindered or terminated by excessive negative resident reaction toward tourism development [13]. Therefore, tourism planners must take into account the views of the local residents if the industry is to be sustainable in the long run [13]. 


\section{Methods}

To examine local Sabahans' satisfaction with the level of access to Mount Kinabalu, two indicators were analyzed: 1) number of complaints by local Sabahans regarding access; and 2) perception of change in accessibility. A survey was conducted to assess local Sabahans' perception of change in accessibility. Using convenient sampling method, self-administered questionnaires were distributed in local villages, educational institutions and shopping malls. Additionally, for the first indicator, secondary data sources (e.g. print and online articles) were used and interviews with both SP and SSL were conducted.

\section{Results and Discussion}

\subsection{Profile of Respondents}

Of the 300 questionnaires distributed, 263 questionnaires were returned. 14 incomplete questionnaires were excluded. Table 1 shows there were an almost equal number of male (49.2\%) and female $(50.4 \%)$ respondents. Almost half of the respondents (49.2\%) were aged between 20 and 30 years. All of the respondents had completed some level of education: high school or equivalent $(28.6 \%)$, some college (30.2\%) and a Bachelor's Degree (23.8\%). The majority of them (81\%) were native Sabahans, Kadazandusun. Almost all of the respondents $(92.3 \%)$ had a source of income with almost half of them (47.8\%) earning less than RM2000 per month and 34.4\% are earning between RM2001 and RM5000 per month. Only $38.6 \%$ of the respondents had previously climbed Mount Kinabalu.

Table 1. Profile of Respondents $(n=249)$.

\begin{tabular}{|c|c|c|c|c|c|}
\hline & Items & $\%$ & & $\mathrm{~ms}$ & $\%$ \\
\hline Gender & $\begin{array}{l}\text { Male } \\
\text { Female }\end{array}$ & $\begin{array}{l}49.2 \\
50.4\end{array}$ & Source of income & $\begin{array}{l}\text { Yes } \\
\text { No }\end{array}$ & $\begin{array}{l}92.3 \\
7.3\end{array}$ \\
\hline Age & $<20$ years & 5.6 & $\begin{array}{l}\text { Average monthly } \\
\text { income }\end{array}$ & $<$ RM1000 & 26.3 \\
\hline & $20-30$ years & 49.2 & & RM1001 - RM2000 & 21.5 \\
\hline & $31-40$ years & 27.4 & & RM2001 - RM3500 & 19.0 \\
\hline & $41-50$ years & 12.5 & & RM3501 - RM5000 & 15.4 \\
\hline & $>51$ years & 5.2 & & RM5001 - RM7500 & 5.3 \\
\hline $\begin{array}{l}\text { Highest } \\
\text { level of }\end{array}$ & High school or equivalent & 28.6 & & RM7501 - RM10000 & 2.4 \\
\hline education & Vocational or technical school & 0.8 & & $>$ RM10000 & 2.8 \\
\hline & Some college & 30.2 & $\begin{array}{l}\text { Have you climbed } \\
\text { Mount Kinabalu? }\end{array}$ & Yes & 38.6 \\
\hline & Bachelor's Degree & 23.8 & & No & 61.4 \\
\hline & Master's Degree & 13.7 & & & \\
\hline & Doctoral Degree & 2.8 & & & \\
\hline Ethnicity & Malay & 12.9 & & & \\
\hline & Chinese & 5.6 & & & \\
\hline & Indian & 0.4 & & & \\
\hline & Native Sabahans & 81.0 & & & \\
\hline
\end{tabular}




\subsection{Number of Complaints Regarding Access}

Following the increases in accommodation rates, complaints were lodged by various parties, including prospective climbers, repeat climbers as well as local and foreign tour operators. Many of them claimed that the price was drastic and unjustifiable. They criticized that the price increases had not translated into better maintenance of facilities: hot water still interrupted; electricity and plumbing leaks still happening. Some expressed their concerns that Mount Kinabalu might become out of reach for many Malaysians due to the astronomical accommodation rates.

They also questioned the inclusion of meals in the accommodation rates in the name of conservation. In their judgment, the packed lunch using polystyrene boxes and plastic bags were actually producing more rubbish on Mount Kinabalu [7-8]. Another major complaint centered upon the extensive waiting time to wrangle a spot to climb Mount Kinabalu. It would take several months in advance to acquire a confirmed booking. A Facebook petition called 'Mount Kinabalu - belongs to NO ONE else' was established and over 1000 people signed it [7-8]. However, the researchers failed to locate the petition as it has most probably been removed.

The researchers made an attempt to locate any recent complaints published online or in print, but none were discovered. A recent interview with SP and SSL disclosed that they have not received any formal complaints lately. The SSL representatives explained that the common complaint they do receive recently focuses on the shortage of hot water supply and electricity on Mount Kinabalu, which is rather beyond their control since it is not uncommon that hot water supply and electricity are scarce in high altitude places.

Commenting on the complaint regarding Mount Kinabalu being too expensive for local Sabahans to climb, the SP representatives expounded that the introduction of Sabahan rate (RM80 for accommodation and meals, excluding permit, insurance, porter and guide fee; offered on a 25 Sabahan-daily basis) has helped resolve the issue to a significant extent, although on rare occasions they do encounter local Sabahans who insist on paying the Sabahan rate even when the quota has already been reached.

The SSL representatives commented that most of the complaints were not made by Sabahans, and that they were lodged by those who were not well informed about the justification behind the increased accommodation rates. As indicated in Figure 1, over half of the respondents (51.04\%) who have previously climbed Mount Kinabalu paid a total of less than RM200, and more than a quarter $(36.46 \%)$ paid between RM201 and RM400.

The majority of them (75\%) think the total cost was reasonable. When asked how much the climbing cost should be for Sabahans, $72.6 \%$ of all the respondents think it should be less than RM200, which is precisely what the Sabahan rate is offering. The Sabahan rate is limited to only 25 Sabahans daily. When this quota is reached, the next interested Sabahan climbers will have to pay the general Malaysian packages, cheapest of which is RM329.00 [14].

Commenting on the extensive waiting time to get a confirmed booking, the SP and SSL representatives justified that Mount Kinabalu has become a globally renowned tourist attraction; therefore it is expected that the demand to climb the mountain is increasing. Nevertheless, in the name of preservation and conservation, the limit on the daily number of climbers (192 climbers at a time) has to be maintained, hence the long waiting time. When queried how far in advance one is advised to make a reservation, the SP representatives explained that there really is no pre-determined time as to how far in advance one should make a booking, but it is highly recommended to book as far in advance as possible.

As shown in Figure 1, the waiting time to obtain a confirmed booking does not seem overly lengthy. Over half $(59.38 \%)$ of respondents who have climbed Mount Kinabalu reported that it took them less 2 months to get a confirmed booking. In our viewpoint, such length of waiting time is not uncommon in eminent tourist destinations that do impose a limit on the daily number of visitors. For instance, prospective climbers of Mount Everest are advised to pick the date for their climb at least six months beforehand [15]. To trek the Inca Trail in Peru, one is recommended to make a booking as far in advance as possible as one knows the dates of his/her international flight [16]. 


\subsection{Perception of Change in Accessibility}

Accessibility is measured by two factors, namely climbing cost and waiting time to acquire a confirmed booking. As shown in Figure 2, nearly half of the respondents $(43.75 \%)$ who have previously climbed Mount Kinabalu perceive the mountain to be less accessible for local Sabahans now because the present climbing cost is less affordable. Additionally, a rather high number of those respondents (32.29\%) perceive Mount Kinabalu to be less accessible for local Sabahans now because it takes a longer time to get a confirmed booking.

For respondents who have not climbed Mount Kinabalu, nearly half of them $(42.69 \%)$ do not know if Mount Kinabalu is now more or less accessible for local Sabahans in terms of climbing cost and waiting time. Nevertheless, about a quarter of those respondents $(23.03 \%)$ feel that Mount Kinabalu is now more accessible because it now takes a shorter time to get a confirmed booking. Although more than a quarter of them (30.72\%) perceive the climbing cost to be less affordable now, it does not seem to make them feel that Mount Kinabalu is less accessible for local Sabahans due to cost.

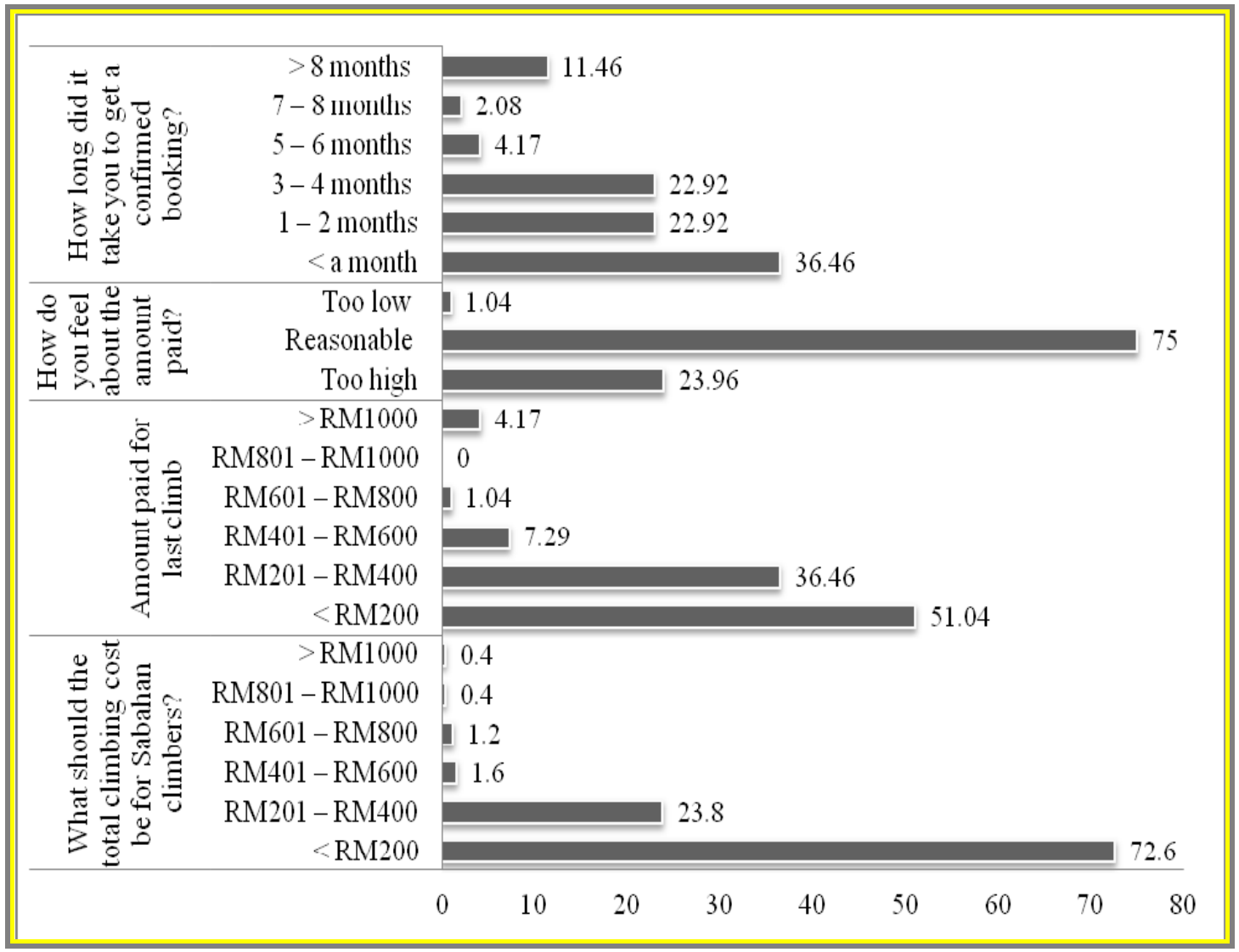

Figure 1. First Question for All Respondents $(n=249)$; the Next Three Questions for Respondents who have Previously Climbed Mount Kinabalu $(\mathrm{n}=96)$ 


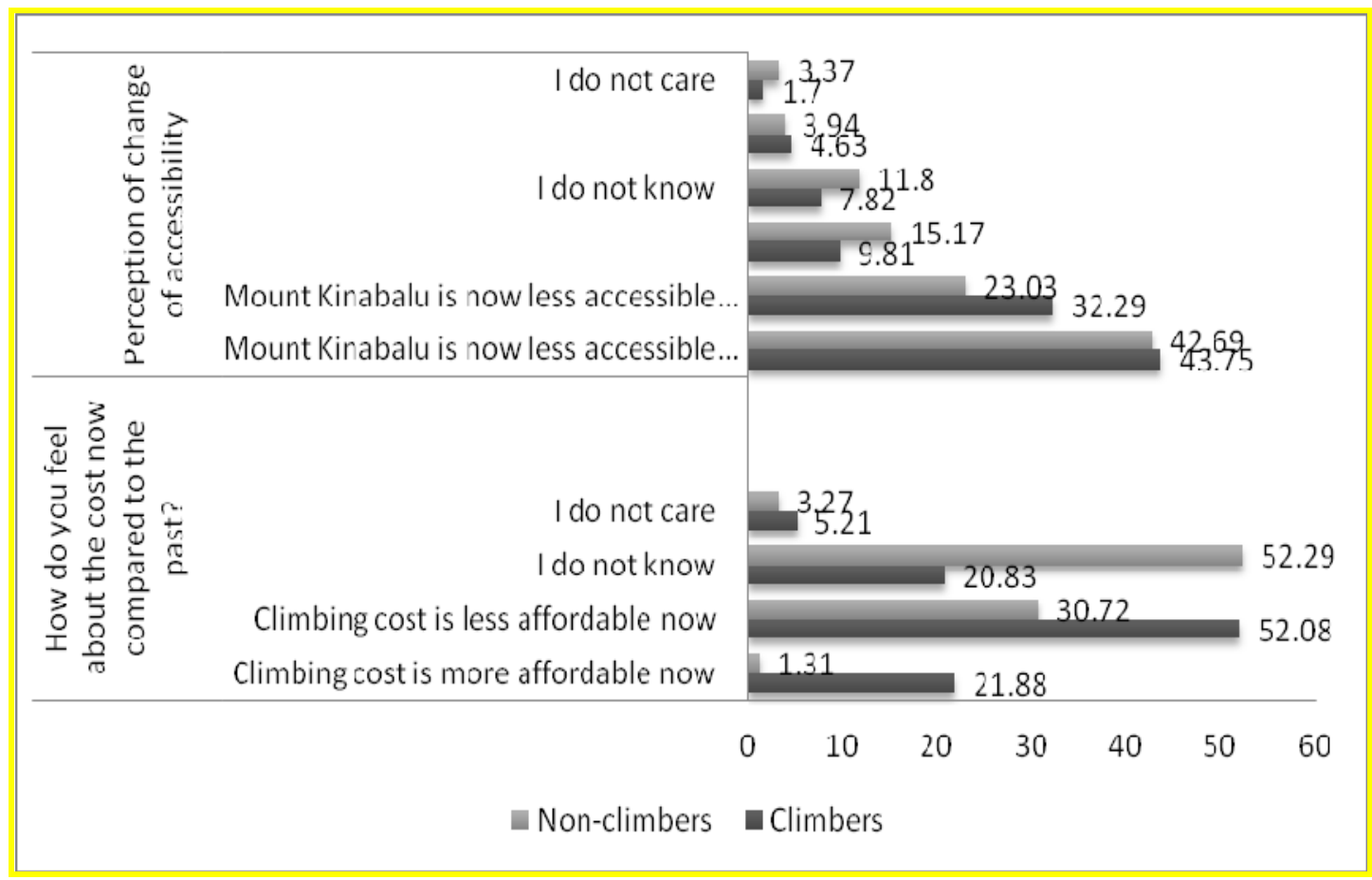

Figure 2. Perception of Changes in Accessibility

\section{Conclusion}

Local Sabahans' satisfaction with the level of access to Mount Kinabalu may be pictured as a calm lake that is extremely susceptible to the forming of ripples by the cast of a stone into it. Following closely the rise in accommodation rates in Kinabalu Park, the number of complaints lodged was intense. However, the 'storm' subsided with introduction of the more affordable Sabahan rate and improvement of visitor facilities and services on Mount Kinabalu. Complaint regarding access (climbing cost and waiting time to get a confirmed booking) seems to be minimal these days. But it does not necessarily mean all is fine and peaceful. While complaint may act as a warning system for emerging discontent, it neither monitors all opinions nor monitors any opinions continuously. Thus, it is crucial to assess the local reaction toward the satisfaction with level of access to Mount Kinabalu. Overall, local Sabahans perceive the access to Mount Kinabalu has changed. Those who have previously climbed Mount Kinabalu think the mountain is less accessible for local Sabahans now because the climbing cost is less affordable and it takes a much longer time to secure a confirmed booking. Those who have not climbed Mount Kinabalu share the opinion that the climbing cost has become less affordable, but they do not necessarily think of that as contributing to the less accessibility of Mount Kinabalu for local Sabahans. If care is not exercised to ensure a satisfactory level of access to Mount Kinabalu for local Sabahans or to ensure local Sabahans have a continued fair and equal access to Mount Kinabalu, a storm might just strike again.

\section{Acknowledgements}

We would like to express our heartfelt gratitude to Mr. Rodzan Pengiran Dahlan and Mr. Anthony Tinggi from Sabah Parks, and Mr. Henry Balenting and Mr. Adrian Alaska from Sutera Sanctuary Lodges for their valuable time and cooperation in providing the information required for the writing of this paper. 


\section{References}

1. World Tourism Organization, Indicators of sustainable development for tourism destinations: a guidebook (World Tourism Organization, Madrid (2004)

2. http://www.odi.org/sites/odi.org.uk/files/odi-assets/publications-opinion-files/2861.pdf

3. http://www.ahs.uwaterloo.ca/rec/pdf/inttrends.pdf

4. www.twnside.org.sg/title/tourism.doc

5. http://hss.ulb.uni-bonn.de/2008/1288/1288.pdf

6. H.C. Goh, M.M. Yusoff, Int. J. Trade. Eco. Financ. 1,2, 179-183 (2010)

7. http://www.newsabahtimes.com.my/nstweb/fullstory/25505

8. http://www.thestar.com.my/story.aspx/?file $=\% 2 \mathrm{f} 2009 \% 2 \mathrm{f} 1 \% 2 \mathrm{f} 31 \% 2 \mathrm{flifetravel} \% 2 \mathrm{f} 3107154 \& \sec$ $=$ lifetravel

9. R. Sharpley, Tourism Manage. 42, 37-49 (2014)

10. C. Jurowski, D. Gursoy, Ann. Tour. Res. 31,2, 296-312 (2004)

11. T. Snaith, A. Haley, Tourism Manage. 20,5, 595-603 (1999)

12. R. Lawson, J. Williams, T. Young, J. Cossens, Tourism Manage. 19,3, 247-256 (1998)

13. J. Williams, R. Lawson, Ann. Tour. Res. 28,2, 269-290 (2001)

14. http://www.mysabah.com/download/mt-kinabalu-laban-rata-room-rates.pdf

15. www.ratestogo.com/blog/climbing-mount-everest/

16. http://www.perutreks.com/inca_trail_04d_faq.html 